\title{
Sciendo
}

Rocznik Pedagogiczny 42/2019

PL ISSN 0137-9585

DOI $10.2478 /$ rp-2019-0011

FANI ALEZRA

Gordon College of Education in Haifa

\section{THE IMAGE OF A KINDERGARTEN TEACHER IN THE ISRAELI MEDIA}

Every few days we see media headlines about kindergarten teachers, and the vast majority deal with violence, abuse, and child molestation. Publications on this issue generate great public interest and appear in all types of media and news, since these news items are significant and touch almost every one of us as parents or grandparents, as human beings who sense helplessness. As a result, the profession of the kindergarten teacher is viewed harshly by the public and has an image lower than that of teachers. The purpose of this article is to examine the concept of the teacher's image in the media, try to explain it, and offer ideas for improvement.

\section{THE IMAGE OF THE KINDERGARTEN TEACHERS}

The committee of experts assembled in the United States with the aim of recruiting high- quality personnel for teaching ${ }^{1}$ stated that work conditions, salary, and social image are influential factors: when the level of salary and work conditions increase, the status of the profession rises, a change is created in the perception of the profession, and it attracts appropriate candidates and gets results ${ }^{2}$. The McKinsey Report ${ }^{3}$ creates a direct relationship between teacher quality, teacher

1 M. Cochran-Smith, Constructing Outcomes in Teacher Education: Policy, Practice, and Pitfalls, "Educational Policy Analysis Archives" 2001, 9 (11); L. Darling-Hammond, Solving the Dilemmas of Teacher Supply, Demand, and Standards: How We Can Ensure a Competent, Caring, and Qualified Teacher for Every Child, National Commission on Teaching and America's Future, New York 1999.

2 J.S. Chall, The Academic Challenge: What Really Works in the Classroom? Gilford, New York 2000

3 McKinsey Report, How the World's Best-Performing School Systems Come Out on Top, 2007, $<$ http://www.mckinsey.com/clientservice/socialsector/resources/pdf/Worlds_School_systems_ final.pdf $>$. 
status, and professional prestige. In countries where the profession suffers from a low status it attracts less talented candidates and the status of teaching declines, and with it the quality of people it can attract.

Fisherman ${ }^{4}$ in his book on professional identity and burnout among educators describes the situation in Israel: the teacher's status is steadily declining as a result of the shattering of the ideal of the state. Ben Peretz ${ }^{5}$, who studies the training of teachers in Israel, lists many factors that influence the teacher's professional status, including the preliminary requirements for entry into the profession, education and skills required to engage in it, economic resources allotted to the field, salary and working conditions, and benefits related to the profession.

The kindergarten teacher's image is even lower than the teacher's image and is more complicated. Stodney ${ }^{6}$ presents research studies indicating a gap between kindergarten teachers' perception of their role and how they actually perform. On the one hand, they accept their choice and have professional pride and great love of the profession. On the other hand, the reality does not fit the ideal and value-based perceptions of their role. In her opinion, the reason is that the work in the kindergarten entails great difficulty in terms of the responsibility assigned to kindergarten teachers and in terms of the multiplicity and complexity of assignments. Kindergarten teachers report difficulties such as management of the system of relationships with different members of the kindergarten staff and with additional factors outside of the kindergarten and in the work with the parents. Sometimes this work is perceived as the most complicated and difficult component in the kindergarten teacher's role. This perception derives from society's expectations from the kindergarten teacher when these expectations are not defined in an especially realistic manner in light of conditions under which the kindergartens operate ${ }^{7}$.

Oshrat $^{8}$ also notes the difficulties that cause the kindergarten teacher's low professional image. In her opinion, the kindergarten teachers work with little professional assistance and meet parents on a daily basis. In addition to the teaching and education roles, the kindergarten teacher is the manager of the kindergarten.

4 S. Fisherman, Professional Identity and Burnout among Teaching Workers, Shanan Press, Haifa 2016.

5 M. Ben-Peretz, Policy Making in Education: A Holistic Approach Responding to Global Changes, Rowman \& Littlefield Publishers, Maryland 2009.

6 M. Stodney, Organizational Citizenship Behavior of Kindergarten Teachers in Israel, Ph.D. Dissertation, Tel Aviv University, 2009.

7 M. Stodney, Organizational Citizenship Behavior of Kindergarten Teachers in Israel, Ph.D. Dissertation, Tel Aviv University, 2009.

8 S. Oshrat, Stress and Burnout among Kindergarten Teachers, "Studies and Research in Teacher Training" 1999, 6, 94-119. 
Other researchers ${ }^{9}$ address the gap between the difficulty with work in early childhood education and the low image of the profession and the kindergarten teacher in the public. In their opinion, this gap derives from lack of awareness of the high intellectual requirements of the profession and from the fact that their work is perceived as the work of mothers. They believe that a definition suitable for the profession that would allow practitioners to understand the uniqueness in their professional role and convey it to others is lacking. As aforementioned, there is overwhelming agreement about the complexity of the kindergarten teacher's role. Society recognizes the importance and necessity of the education profession, but its image is low ${ }^{10}$.

The status of the teacher in Israel is inferior to the status in the OECD countries. Most students in the early childhood education program are women; very few men learn in this program, no more than fifteen a year. Most men go to private kindergartens. The women students are not of the highest level, in social-economic terms and in academic achievements ${ }^{11}$. In the year 2017, about $99.2 \%$ of the kindergarten education practitioners in Jewish state education are women and only $0.8 \%$ men. In state religious education this figure is lower, and in Arab education it is $0 \%{ }^{12}$.

Among researchers there is a difference of opinion about the importance and centrality of the salary and its influence on the image of the teaching profession in contrast to other variables, such as work conditions, public perception of the teaching profession, or others who maintain that the teacher can influence the image of the profession ${ }^{13}$. Hoyle ${ }^{14}$ maintains that the professional assessment of teachers depends on them and only they can improve it, through display of expertise, mastery of skills of teaching, and great commitment to children's success.

${ }^{9}$ L.S. Goldstein, Teaching with Love: A Feminist Approach to Early Childhood Education, Peter Lang, New York 1998; K. Johnston, C. Brinamen, Integrating and Adapting Infant Mental Health Principles in the Training of Consultants to Childcare, "Infants \& Young Children" 2005, 18 (4), 269-281.

${ }^{10}$ D. Magan, Design Aspects of Manpower in Teaching and Training for Teaching, Central Bureau of Statistics of Israel, 2015.

${ }^{11}$ M. Trachtenberg, Report of the Committee for Social Economic Change, Jerusalem 2011, 107117.

${ }_{12}$ Central Bureau of Statistics, Table 2: Teaching Workers in Kindergarten Education according to Supervision and Select Traits, Tables, Figures, and Maps, Central Bureau of Statistics, Israel, 2019.

${ }^{13}$ N. Blass, Review of the Literature and Description of a Case on the Topic of the Improvement of the Attractiveness of the Teaching Profession. Submitted to the Initiative for Applied Research in Education, Staff of Experts for the Activity Who Will Teach When Teachers Are Lacking?, Ministry of Education, Israel, 2009.

14 E. Hoyle, Teaching: Prestige, Status, and Esteem, "Educational Management \& Administration" 2001, 29 (2), 139-152. 


\section{MEDIA AND SOCIAL IMAGE}

The media has the power to change opinion, is part of a culture that shapes reality for us, is dominant in our lives as major information providers and powerful determinants of the public and current agenda, and influences the quality of life in a democratic society ${ }^{15}$. The power of the media lies in the organization, design, and sorting of information, when these divisions are in fact representations ${ }^{16}$.

The concept of social representations coined by Moskovici ${ }^{17}$ originated in the term collective representations. Durkheim called collective representations forms of internalized knowledge or beliefs existing in pre-modern societies and they are used to maintain cohesion and stability of society. In some situations, social images of social reality blur the boundaries between real and real representation and are difficult to discern.

According to Moskovici ${ }^{18}$, the mass media is a powerful source of participation in building social representations. The expanding circle of influence of modern media has accelerated the process of social representation. Social representations are a very important part of building our world and perception of reality, allowing us to understand communication between humans and different groups. Identifying social representations, revealing their origins, and revealing the social relationships that led to their formation can undoubtedly contribute to a broader understanding of cultural and social activity ${ }^{19}$.

It should not be overlooked that building a collaborative communication world may impart or reinforce distorted ideas, including stereotypical prejudice. A stereotype is a (generally negative) perception of a social group, with simplistic representations of outer appearance, character, and beliefs. Stereotypes illustrate important attitudes and power relations toward categories of people in a particular society at a given time. These categories include nationality, race, gender, class, age, sexual preference, and profession. Stereotypes are based on media repetition as well as everyday discourse. Stereotypes are characterized as instantly recognizable ${ }^{20}$. A stereotype has implications for the self-image, how a person perceives himself and his image in the eyes of others. Stereotypes are powerful and are

${ }^{15}$ M. Feuerstein, Speaking Current Events: Literacy and Communication, Mofet Institute, Raanana 2016, 117-138, 203-229.

${ }^{16}$ S. Elbaz, Minority Opinion in the Hebrew Press, Squid Publishing, 2013, 27-30.

${ }^{17}$ S. Moscovici, Why a Theory of Social Representations?, [in:] K. Deaux, G. Philogene (eds.), Social Representations: Introductions and Explorations, Blackwell, Oxford 2001.

${ }^{18}$ S. Moscovici, Why a Theory of Social Representations?, [in:] K. Deaux, G. Philogene (eds.), Social Representations: Introductions and Explorations, Blackwell, Oxford 2001.

19 A. Farah Bidjari, Attitude and Social Representation, Procedia-Social and Behavioral Sciences, Faculty of Education and Psychology, Alzahra University, Vanak, Tehran, Iran, 2011.

20 J.W. Burton, Conflict: Resolution and Prevention, St. Martin's Press, New York 1990. 
practiced almost without thinking ${ }^{21}$. When we treat a person in stereotypically, we attribute to him certain traits inferred only from his affiliation.

One category of this concept is perception toward professional groups. When we hear the group name, we have images relating to language, education, physical abilities, and appearance of group members. Representation sets stereotypes in relation to groups. Representation is the image, reflection or reconstruction of something of the "real" world, referring to how different aspects of reality are constructed (people, objects, events, places, ideas) and presented in the media. Representation in the media often creates a discrepancy between reality and representation; representations are selective, limited or framed unanimously and are the result of mechanical processing or mediation ${ }^{22}$.

Social comparison theory ${ }^{23}$ holds that we formulate knowledge of ourselves by the social environment and value ourselves by comparing to attitudes and abilities of others, usually similar to us. Another significant phenomenon in the foreign group's homogeneous illusions is we tend to assume we are special and different from each other, while "they" are all the same. One explanation suggests the illusion stems from the gap in the amount of information we have on the interior and exterior group, i.e. lack of knowledge, due to differences in familiarity with members of the two groups. We are motivated to evaluate the variance in the interior group as higher ${ }^{24}$. This theory can help us understand society's view of kindergarten teachers and child caregivers as the same ${ }^{25}$.

\section{MEDIA AND REALITY}

The media is a major arena for representing reality, but does it reflect reality or create reality? Hall ${ }^{26}$ presents three major theories dealing with the representation of reality and relevant to the discussion of communication: the reflective approach holds that meaning lies in the object; the intentional theory

${ }^{21}$ J. Turner, Towards a Cognitive Redefinition of Social Group, [in:] H. Tajfel (ed.), Social Identity and Intergroup Relations, Cambridge University Press, Cambridge 1982.

22 D. McQueen, Representation and Stereotyping, Television - A Media Student's Guide, Arnold, London 1998, 139-160.

${ }^{23}$ L. Festinger, A Theory of Social Comparison Processes, "Human Relations" 1954, 7 (2), 117 140.

${ }^{24}$ T.D. Gilbert, R.B. Giesler, K.A. Morris, When Comparisons Arise, "Journal of Personality and Social Psychology" 1995, 69, 227-236.

25 S. Rox, J.M. Schwartzold (eds.), Social Psychology Unit 3-4, The Open University, Tel Aviv 2000.

${ }^{26}$ S. Hall (ed.), Representation: Cultural, Representations and Signifying Practices, Sage Publications, London 1997. 
is a mirror image opposite to the reflective one; and the constructionist theory combines the two previous ones and assumes there is interaction between subject and object. This is a dialectical approach: I change reality and at the same time am changed by it.

In addition, various approaches are based on different models that relate to the concept of media and graphically describe processes taking place in the media. Laswell's model ${ }^{27}$ describes the media process as five questions: Who will? Say what? Who is? On which channel? And what effect? It is a linear model that describes the media process as a one-way process: the message is conveyed from sender to recipient through the communication medium and the recipient is influenced by the message. The recipient is passive. In contrast, De Fleur's model ${ }^{28}$ refers to feedback from the sender; it is not completely symmetrical. The sender is still a major source of messages, while the recipient's messages are defined as feedback. De Fleur's model, in contrast to the previous model, accounts for interruptions in communication processes and calls them "noise". This model removes the responsibility from the message and shifts it, at least partially, to the recipient of the message.

In the linear model, Cary ${ }^{29}$ based on two approaches to understanding the place and role of media in society. One approach sees the media as a means of transmitting messages. The second approach argues this is not a transfer but a convergence. The media brings people together around common symbols and values and creates a collaborative sense of community. Either way, we see the power of the media in shaping everyday reality and influencing public opinion. Goren ${ }^{30}$ refers to the formative approach that has no single objective truth but truth to the journalist who covers it.

The mass media is involved in building perceptions of reality and is a major source of information for shaping perception of phenomena ${ }^{31}$. There is a distinction between short-term and long-term influence. In the short term, this is a passing and changing influence, like fashion styles. In the long term, this is influence on beliefs and perceptions. There is also influence on the individual and his behavior and influence on society at large, on the micro and macro levels.

${ }^{27}$ Laswell, 1948, [in:] D. Kaspy, Y. Limor, Mass Media, Volume 1, Units 1-4, The Open University, Ramat Aviv 1992, 13-15.

${ }_{28}$ DeFleur, 1968, [in:] D. Kaspy, Y. Limor, Mass Media, Volume 1, Units 1-4, The Open University, Ramat Aviv 1992, 13-15.

${ }^{29}$ G. Cary, Approach to Communication as a Culture, [in:] T. Libs, M. Talmon (eds.), Communication as Culture - A Reader, Volume 1, The Open University, 2003, 79-98.

${ }^{30}$ D. Goren, The Media and Democracy in Israel, [in:] Noyberger, Coopman, Shemshi (eds.), Government and Politics, Am Oved, Tel Aviv 1993, 323-333.

${ }^{31}$ L. Grossberg, E. Wartella, C.D. Whitney, Media Making, Sage, London 1998. 
Repetitive messages and images create a common symbolic environment ${ }^{32}$. In the postmodern era, images and media models determine reality more than represent $i^{33}$ and consist of two levels, dictionary meaning and social meaning, anchored in the recipient's culture and world.

As media technologies become more sophisticated and their presence in the everyday life of the audience increases, the issue of media effects becomes more complex ${ }^{34}$.

\section{MEDIA AND IMAGE CREATION}

In our era, there is often criticism of the education system. The media does not represent exemplary figures from teaching or unique projects ${ }^{35}$.

Examining the teacher's representation in the media will help examine the teacher's image. The media and education are both academic disciplines, which encompass culture, have social, cultural, and emotional roles, and act as mediators for the general public ${ }^{36}$.

Turin $^{37}$, in one of the few studies on the subject in Israel, refers to the figure of the teacher in the elementary school and high school and not to the kindergarten teacher. She investigates the teacher's image in three fields: the cinema, the media, and the press. She concludes the image of the teachers is ridiculous and negative and provokes public distrust of the difficulty and wage demands. She refers to the gendered nature of the profession, mostly made up of women, and the characters of teachers in television comedies that cultivate an image that becomes reality in Israeli society. Moreover, she attributes negative media coverage of teachers to hidden interests she calls a secret conspiracy by heads of universities, who want to discredit the academic level of the teacher education colleges and thus emphasize their advantage. In her opinion, it is also a plot of the Ministry of Finance to keep the salaries of teachers ${ } \mathrm{wow}^{38}$.

${ }^{32}$ G. Gerbner, L. Gross, M. Morgan, N. Signoriella, Living with Television: The Dynamics of the Cultivation Process, [in:] J. Bryant, D. Zillman (eds.), Perspectives on Media Effects, NJ: Lawrence Erlbaum Associates, Hilldale 1986, 17-40.

33 R. Barthes, The Photographic Message in Image, [in:] Image, Music, Text, Fontana Press, London 1977, 15-51.

${ }^{34}$ M. Feuerstein, Speaking Current Events: Literacy and Communication, Mofet Institute, Raanana 2016, 117-138, 203-229.

35 E. Wolansky, International Trends and Implications for Israel, Becoming a Teacher, 2011, 23-55.

${ }^{36}$ K.E. Rosengren, Media Linkages of Culture and Other Societal Systems, Communication Yearbo$o k, 1985,9,19-56$.

37 A. Turin, Representations of Teachers in Israeli Media, Mofet Institute, Raanana 2014.

38 A. Turin, Representations of Teachers in Israeli Media, Mofet Institute, Raanana 2014. 
The literature review presents the bleak situation of the kindergarten teacher well as the power and significance of the media. The present article addresses the characteristics of media publications on kindergartens and aims to examine the image in the media in an attempt to understand it and thus suggest ways to improve this image.

\section{RESEARCH QUESTION}

How is the kindergarten teacher's image expressed in publications about the kindergarten and kindergarten teacher in media in Israel?

\section{METHODOLOGY}

The method chosen is content analysis, a research technique for the objective description of media content through which messages can be identified so that the choice of content must be objective and motivated ${ }^{39}$. Berelson ${ }^{40}$ and Guba and Lincoln ${ }^{41}$ state that the content analysis method can find encrypted messages in the content and not assumptions and questions forced on the text. It is important to note that in other content sites the publications on this topic are quite similar. The process of content analysis requires the construction of a category system while searching for prominent elements, between theory and the material under study ${ }^{42}$.

The research instruments are ten articles from the last four months with the kindergarten tag on the content sites News Walla and Mako.

1. The difficult documentation from the kindergarten in Tel Aviv that led to the opening of an investigation. 20/8/19. <https://www.mako.co.il/newslaw/2019_Q3/Article-b62c2c8f70fac61027.htm>.

2. The kindergarten teacher humiliated the 5-year-old: "Go from my kindergarten, the kids don't want you". 18/8/19. <https://www.mako.co.il/tvmorning-news/articles/Article-e5a9771f923ac61027.htm>.

3. You do not want to know what is happening in your children's kindergarten. 9/8/2019. <https://www.ynet.co.il/articles/0,7340,L-5565865,00. html>.

39 O.R. Holsti, Content Analysis for the Social Sciences and Humanities, Addison-Wesley, Reading, MA 1969.

${ }^{40}$ B. Berelson, Content Analysis in Communication Research, The Free Press, New York 1952.

${ }^{41}$ E.G. Guba, Y.S. Lincoln, Effective Evaluation, Jossey-Bass, San Francisco 1981.

${ }^{42}$ N. Sabar-Ben Yehoshua, Qualitative Research in Teaching and Learning, Givatayim, Masada 1990. 
4. Will sanctions be imposed on parents who record in the kindergarten? 23/7/19. <https://www.ynet.co.il/articles/0,7340,L-5555286,00.html>.

5. Seven convictions in a decade: Courts are in no hurry to send abusive kindergarten teachers to prison. 19/7/18. <https://news.walla.co.il/ item/3166919>.

6. I am closing the kindergarten because parents no longer trust us. 17/7/19. <https://www.mako.co.il/home-family-toddlers/education/Article-3e6826db01ffb61027.htm?partner=tagit>.

7. Three Gush Etzion kindergarten teachers were arrested on suspicion of abusing infants 14/7/19. <https://13news.co.il/item/news/domestic/ crime-law/crime/abuse-kindergarten-300539/>.

8. The fight against violence against toddlers. 11/7/19. <https://www.mako. co.i1/news-channel2/Channel-2-Newscast-q3_2019/Article-1295dada122eb61027.htm?partner=tagit $>$.

9. It is forbidden to discredit the entire public of kindergarten teachers. 9/7/10. <https://www.mako.co.il/news-columns/q3_2019/Article-da11a$3 \mathrm{~d} 3 \mathrm{ec} 5 \mathrm{db} 61026 . \mathrm{htm}$ ?partner=tagit>.

10. The abusive kindergarten teacher: The method was "punch and hug", to punch and then say "I love you". 29/6/19. <https://www.mako.co.il/tvmorning-news/articles/Article-b951159fe529b61027.htm>.

\section{ANALYSIS}

The topics of the articles demonstrate the tendency to choose the negative aspects. There is no attempt to balance with other types of publications. Usually the journalist presents the parent's viewpoint, with no other perspectives. The headlines are short and use the word abuse. There is description of criminal acts, cruelty, and abuse. The topics were chosen from the perspective of the parents presented by the journalist.

\section{Headlines}

There is a misleading generalization that refers to care workers and kindergarten assistants as kindergarten teachers. In the Hebrew language, the term kindergarten teacher has become a general term also incorporating auxiliary untrained or mostly untrained personnel. The articles use other terms (daycare workers, nannies), but after the use of kindergarten teacher in the title the impact of other terms is negligible. This situation is similar to confusion between auxiliary hospital staff and nurses; it is inconceivable to place them into one group. 
Barthes $^{43}$ explained this on two levels: the nickname, or the dictionary meaning, and the connotation, or the auxiliary meaning, grounded in the person's culture and world. The person hears kindergarten teacher but for him a kindergarten teacher has the same role as care worker and kindergarten assistant. The parents call all people working in the kindergarten kindergarten teachers.

This issue raises the question of the name and meaning of the profession and implies that perhaps there should be a change of name or a definition of who can bear the name kindergarten teacher, just like a construction worker cannot claim to be an engineer. However, this does not mean that every educated and certified teacher is a proper teacher. Unfortunately some teachers who have certificates and trained for teaching are unworthy.

If we focus on the article headlines, a very difficult picture emerges, with repetitive phrases like devil, monster, abuser, violence, humiliation. The study shows that many readers are content to read the headline and not the article. $80 \%$ of articles are not read in-depth ${ }^{44}$ and the authors are aware of this. There is a discrepancy between the headline and the content of the article. Sometimes we see balance and clarity of the names of the profession: caregiver, nanny, kindergarten assistant, kindergarten teacher. A headline like "You Don't Want to Know What's in Your Child's Kindergarten" (\#3) arouses fear, suspicion, mistrust, and worry and includes the entire kindergarten system.

\section{Contents}

The negative attitude is manifested in the use of harsh negative terms derived from criminality, in crucial formulations. There is a sense of two groups: parents and their enemies. There are pictures of demonstrations with posters highlighting negative words and short videos in which parents demonstrate (\#7). There is an image in the text, in videos written in negative and sharp words that present an extreme and difficult image.

The main theme of the articles is the violence of kindergarten teachers and kindergarten staff toward children. In general, reports of violence, parental comments, and severity of the activities are presented. In one case, when an unusual article presents a dilemma in the title "Will sanctions be imposed on parents who record in kindergarten", there is no proper discussion. There is no attempt to determine what the factors are and how, parents' statements are presented unilaterally,

${ }^{43}$ R. Barthes, The Photographic Message in Image, [in:] Image, Music, Text, Fontana Press, London 1977, 15-51.

${ }^{44}$ C. McLoughlin, M. Northcote, What Skills Do I Need to Teach Online? Search and Research: Teacher Education for Contemporary Contexts. Spain: Ediciones Universidad de Salamanca, 2017, $1119-1129$. 
and a picture of two groups is obtained: parents against kindergarten teachers when the media chose a side. The desire to photograph and record in the kindergarten expresses distrust of kindergarten teachers. There is no proper discussion in the article, and there is a lack of teacher response and perception. Neither the teachers' response nor their perceptions are presented, the opposition of the teachers' unions is highlighted, and only the parents' opinions are presented. There was no dialogue and no process was built to build parents' trust in teachers and the education system.

Another notable feature of the article content is the reference to gender. All female-styled articles depict abusive women, but an article presented on the news on $28 / 6$ in prime time finally excitedly documents positive kindergarten teachers. A great "real kindergarten teacher" does make a good professional impression. What led journalists to create an article about it and to present it in the news? Is it that the teacher is a man and not a woman? Why haven't we seen such articles about women kindergarten teachers? Does such an article contribute to the kindergarten teacher's image or fix the poor image?

What's missing from the content of the articles? There is no positive news about kindergarten teachers depicting unique work, projects, a noted educational figure. In other words, this important issue is not news when it is not negative. In recent weeks, there have been voices trying to defend the profession and differentiate kindergarten teachers who studied the profession and have a license from caregivers. In addition, the Teachers' Union is pressing for a law to regulate the name and definition of the profession in society.

As the literature review showed, there are homogeneous illusions of the exterior group: we tend to assume we are special and different while "they" are all the same. We tend to see more similarities among members of the exterior group than among members of the interior group. One explanation suggests the illusion stems from the disparity in the amount of information we have on the interior and exterior groups, namely lack of knowledge. Most people in our society have no idea what it takes to be kindergarten teachers, what the required education is, what professionalism is required, and many people think it is mainly about playing games with children. A second explanation in the literature review is that the illusion stems from the differences in the importance that the domestic and interior groups have for us. Since the interior group is more important to us, we are motivated to formulate a more accurate concept and thus evaluate the variance in the interior group as higher ${ }^{45}$. This theory can help us understand the media reference to kindergarten teachers and nannies as the same. The kindergarten teachers, the

45 T.D. Gilbert, R.B. Giesler, K.A. Morris, When Comparisons Arise, "Journal of Personality and Social Psychology" 1995, 69, 227-236. 
interior group, are well aware of the differences in training, worldviews, and professionalism between them and care providers but the parents and media consider them to be the same. In the Hebrew language, there is no differentiation in terminology: all workers with children are called kindergarten teachers.

In an unusual article (\#9) the reporter tries to make the distinction and define the kindergarten teacher group. The article "It is forbidden to discredit the entire public of kindergarten teachers" uses a variety of ways to highlight the differences between the groups: color, text, voice, videos. But the article was aired once, and its effect was not felt.

\section{Talkback}

The articles are broadcast in prime time and distributed in the media on the Internet news sites, causing readers to express themselves in talkbacks. The talkbacks are usually violent and blatant, with cursing, obscenities, and unsubstantiated statements, along with pessimistic comments of disbelief in the education system.

Cohen and Neiger ${ }^{46}$ attribute the talkback style to the cultural factor, arguing that the style of blatant violent discourse stems from the culture that characterizes Israeli society when the respondent's goal is to exert power and control in interpersonal relationships. However, a study of online newspaper users' rebuttal disproves this claim, finding that online newspaper editors in Europe who examined, through variables of local culture, the discourse conducted in response also found blatant violent reactions ${ }^{47}$. This reinforces the negative social image of kindergarten teachers in Israel and fuels it.

\section{Conclusions}

First, it is important to define the name of the profession to distinguish between qualified persons and others. To create a positive attitude, there must be positive publicity. Representation of reality must be made more prominent and not remain indifferent to production of distorted reality. Thus, in my opinion, an article such as "Do not discriminate against all kindergarten teachers" (\#9) helps establish the wrong representation and does not change it; to change representation new schemes must be created. New representations threaten the knowledge

\footnotetext{
${ }^{46}$ A. Cohen, M. Neiger, To Talk and to Talkback: An Analysis of Talkback Rhetoric in the Online Press in Israel, [in:] T. Altshuler (ed.) Dot Com Press. Jerusalem: Israeli Institute of Democracy \& Borda Center Ben-Gurion University, 2007, 350-321.

${ }^{47}$ C.A. Weissman, A. Gonen, The Pink Revolution: The Package, An Original Mockery of Israeli Girls, [in:] R. Rosenthal (ed.), Inner Hebrew, Crown, Jerusalem 2011.
} 
we have and lead to instability and eventually to the process of formation of new social representations ${ }^{48}$.

Hence the attempt to shout "this is not us" is a waste of energy, a weak voice that cannot be heard. Instead other positive representations of the profession in society must be built. It is necessary to think on creative ways different from what has been done so far. A reality show such as the one currently broadcast in Israel and around the world, where kindergarteners and social interactions are filmed, can advance the understanding of the importance of the kindergarten and the kindergarten teacher's professional role and contribute to the professional image. But those who sit and interpret the behavior of the children in the program are psychologists. With all due respect, the person who does the work with children in the kindergarten is the kindergarten teacher. She has the knowledge, she is trained. The psychologist can contribute and add but not be the main thing; it was an opportunity to put the kindergarten teacher at the center.

Another way is to create panels on TV shows where professionals, including kindergarten teachers, discuss questions and find solutions to overcome the dilemmas regarding everyday life in kindergarten and home.

In addition to creating and increasing positive publicity, Wolanski ${ }^{49}$ holds that there is room for unique projects: recently the image of the teaching profession has steadily declined and there is no representation of exemplary figures from teaching or unique projects. The Pre-Elementary Education Department of the Israeli Ministry of Education ${ }^{50}$ has begun wonderful work in defining the future kindergarten, allocating resources to enterprising kindergartens, and encouraging kindergarten teachers to produce unique initiatives and projects. But at the same time systematic work must be done on how to publicize and create resonance that will contribute to the image. Projects that have been carried out have not received media coverage. Most projects are publicized on social networks in the kindergarten teachers' community and not outside it. Kindergarten teachers are not aware of the need to publicize. Expert media professionals should be used to address the media image and handle image change. A program must be prepared in collaboration with the Teachers' Union to produce positive imagery for the profession, write about projects and involve the media, and distribute reports. Public opinion reports should be carried out, like the one examining kindergarten par-

${ }^{48}$ S. Moscovici, Why a Theory of Social Representations?, [in:] K. Deaux, G. Philogene (eds.), Social Representations: Introductions and Explorations, Blackwell, Oxford 2001.

49 E. Wolansky, International Trends and Implications for Israel, Becoming a Teacher, 2011, 23-55.

${ }_{50}$ Pre-Elementary Education Department, Thoughts about the Future Kindergarten. Ministry of Education, Pedagogical Administration, Israel, 2019. 
ent satisfaction ${ }^{51}$, which found that a significant majority of parents hold positive perceptions of key aspects of kindergarten climate. About $90 \%$ of parents report high kindergarten satisfaction (their child likes to go to kindergarten, has pleasant experiences in the kindergarten, and feels safe and protected there). About $80 \%$ of parents report positive relationships between the child and the kindergarten staff (the staff cares about the child, is attentive to his requests, and is sensitive to his unique needs). About $85 \%$ of the parents report that the team promotes the child in emotional, social, and educational areas.

Every kindergarten teacher knows that the climate in her kindergarten and her relationships with the children's families depend on her, her language, her values, and her interpersonal skills. In an era when the media is very significant for creating an image, it is not enough to lead a positive climate in the kindergarten; it is necessary to produce it outside the kindergarten on social networks and in the media so as to create a positive image for the profession.

\section{BIBLIOGRAPHY}

Barthes R., The Photographic Message in Image, [in:] Image, Music, Text, Fontana Press, London 1977, 15-51.

Ben-Peretz M., Policy Making in Education: A Holistic Approach Responding to Global Changes, Rowman \& Littlefield Publishers, Maryland 2009.

Berelson B., Content Analysis in Communication Research, The Free Press, New York 1952.

Blass N., Review of the Literature and Description of a Case on the Topic of the Improvement of the Attractiveness of the Teaching Profession. Submitted to the Initiative for Applied Research in Education, Staff of Experts for the Activity Who Will Teach When Teachers Are Lacking?, Ministry of Education, Israel, 2009.

Burton J.W., Conflict: Resolution and Prevention, St. Martin's Press, New York 1990.

Byrnes J.P., Wasik B.A., The Development of Language and Literacy Skills in Children: What Teachers Need to Know, Guilford, New York 2009.

Cary G., Approach to Communication as a Culture, [in:] T. Libs, M. Talmon (eds.), Communication as Culture-A Reader, Volume 1, The Open University, 2003, 79-98.

Central Bureau of Statistics, Table 2: Teaching Workers in Kindergarten Education according to Supervision and Select Traits, Tables, Figures, and Maps, Central Bureau of Statistics, Israel, 2019.

Chall J.S., The Academic Challenge: What Really Works in the Classroom? Gilford, New York 2000.

Cochran-Smith M., Constructing Outcomes in Teacher Education: Policy, Practice, and Pitfalls, "Educational Policy Analysis Archives" 2001, 9 (11).

Cohen A., Neiger M., To Talk and to Talkback: An Analysis of Talkback Rhetoric in the Online Press in Israel, [in:] T. Altshuler (ed.) Dot Com Press. Jerusalem: Israeli Institute of Democracy \& Borda Center Ben-Gurion University, 2007, 350-321.

${ }^{51}$ National Authority for Measurement and Assessment in Education - RAMA, Climate and Pedagogical Environment in the Kindergartens, Attitudes of the Kindergarten Teachers and Parents: Select Findings, Ministry of Education, Jerusalem, 2017. 
Darling-Hammond L., Solving the Dilemmas of Teacher Supply, Demand, and Standards: How We Can Ensure a Competent, Caring, and Qualified Teacher for Every Child, National Commission on Teaching and America's Future, New York 1999.

Elbaz S., Minority Opinion in the Hebrew Press, Squid Publishing, 2013, 27-30.

Farah Bidjari A., Attitude and Social Representation, Procedia - Social and Behavioral Sciences. Faculty of Education and Psychology, Alzahra University, Vanak, Tehran, Iran, 2011.

Festinger L., A Theory of Social Comparison Processes, "Human Relations" 1954, 7 (2), 117-140.

Feuerstein M., Speaking Current Events: Literacy and Communication, Mofet Institute, Raanana 2016, 117-138, 203-229.

Fisherman S., Professional Identity and Burnout among Teaching Workers, Shanan Press, Haifa 2016.

Gerbner G., Gross L., Morgan M., Signorielli N., Living with Television: The Dynamics of the Cultivation Process, [in:] J. Bryant, D. Zillman (eds.), Perspectives on Media Effects, NJ: Lawrence Erlbaum Associates, Hilldale 1986, 17-40.

Gilbert T.D., Giesler R.B., Morris K.A., When Comparisons Arise, "Journal of Personality and Social Psychology" 1995, 69, 227-236.

Goldstein L.S., Teaching with Love: A Feminist Approach to Early Childhood Education, Peter Lang, New York 1998.

Goren D., The Media and Democracy in Israel, [in:] Noyberger, Coopman, Shemshi (eds.), Government and Politics, Am Oved, Tel Aviv 1993, 323-333.

Grossberg L., Wartella E., Whitney C.D., Media Making, Sage, London 1998.

Guba E.G., Lincoln, Y.S., Effective Evaluation, Jossey-Bass, San Francisco 1981.

Hall S. (ed.), Representation: Cultural, Representations and Signifying Practices, Sage Publications, London 1997.

Hecht Y., Struggle for Hegemony in the Online Content Market - The Case of the Talkback, "Internet Magazine of the Israeli Internet Association" 2003.

Holsti O.R., Content Analysis for the Social Sciences and Humanities, Addison-Wesley, Reading, MA 1969.

Hoyle E., Teaching: Prestige, Status, and Esteem, "Educational Management \& Administration" 2001, 29 (2), 139-152.

Johnston K., Brinamen C., Integrating and Adapting Infant Mental Health Principles in the Training of Consultants to Childcare, "Infants \& Young Children" 2005, 18 (4), 269-281.

Kaspy D., Limor Y., Mass Media, Volume 1, Units 1-4, The Open University, Ramat Aviv 1992, $13-15$.

Kaspy D., Pictures in the Mind: Public Opinion and Democracy, The Open University, Tel Aviv 2001, 150-165.

Magan D., Design Aspects of Manpower in Teaching and Training for Teaching, Central Bureau of Statistics of Israel, 2015.

McKinsey Report, How the World's Best-Performing School Systems Come Out on Top, 2007, $<\mathrm{http} / / /$ www.mckinsey.com/clientservice/socialsector/resources/pdf/Worlds_School_systems_ final.pdf $>$.

McLoughlin C., Northcote, M., What Skills Do I Need to Teach Online? Search and Research: Teacher Education for Contemporary Contexts. Spain: Ediciones Universidad de Salamanca, 2017, 1119-1129.

McQueen D., Representation and Stereotyping, Television - A Media Student's Guide, Arnold, London 1998, 139-160.

S. Moscovici, Why a Theory of Social Representations?, [in:] K. Deaux, G. Philogene (eds.), Social Representations: Introductions and Explorations, Blackwell, Oxford 2001. 
National Authority for Measurement and Assessment in Education - RAMA, Climate and Pedagogical Environment in the Kindergartens, Attitudes of the Kindergarten Teachers and Parents: Select Findings, Ministry of Education, Jerusalem, 2017.

Oshrat S., Stress and Burnout among Kindergarten Teachers, "Studies and Research in Teacher Training" 1999, 6, 94-119.

Pre-Elementary Education Department, Thoughts about the Future Kindergarten. Ministry of Education, Pedagogical Administration, Israel 2019.

Rosengren K.E., Media Linkages of Culture and Other Societal Systems, "Communication Yearbook" 1985, 9, 19-56.

Rox S., Schwartzold J.M. (eds.), Social Psychology Unit 3-4, The Open University, Tel Aviv 2000. Sabar-Ben Yehshua N., Qualitative Research in Teaching and Learning, Givatayim, Masada 1990.

Stodney M., Organizational Citizenship Behavior of Kindergarten Teachers in Israel, Ph.D. Dissertation, Tel Aviv University, 2009.

Trachtenberg M., Report of the Committee for Social Economic Change, Jerusalem 2011, 107-117. Turin A., Representations of Teachers in Israeli Media, Mofet Institute, Raanana 2014.

Turner J., Towards a Cognitive Redefinition of Social Group, [in:] H. Tajfel (ed.), Social Identity and Intergroup Relations, Cambridge University Press, Cambridge 1982.

Weissman C.A., Gonen A., The Pink Revolution: The Package, An Original Mockery of Israeli Girls, [in:] R. Rosenthal (ed.), Inner Hebrew, Crown, Jerusalem 2011.

Wolansky E., International Trends and Implications for Israel, Becoming a Teacher, 2011, 23-55.

Author: Fani Alezra

Title: The Image of the Kindergarten Teacher in the Israeli Media

Keywords: kindergarten teacher, image, publications, Israeli media, headlines, contents, talkback

Discipline: Pedagogy

Language: English

Document type: Article

\section{Summary}

Recognition of the importance of early childhood education is increasing. Many reports published in Israel and around the world deal with the powerful and critical impact of this era on individuals and society. In contrast, the professional image of the kindergarten teacher in Israel is seen as being as low-status as in many countries. This professional image influences the choice of teaching profession and the conditions of admission in teacher training colleges. The low-status image is influenced by many publications in the Israeli media. To say these publications are unflattering to the profession and to kindergarten teachers would be an understatement. In this article, I will try to answer the question: How is the kindergarten teacher's image expressed in publications about kindergarten and kindergarten teachers in the media in Israel? The research tools are ten articles with the kindergarten tag on the news content sites Walla and Mako as of June 2019. The method chosen is content analysis, a research technique for objectively describing media content through which messages can be identified. In so doing, I will draw conclusions about what can be done to improve publications about the profession and at the same time to improve the image of the kindergarten teacher in society. 